\title{
Predictors of Chances to Conceive in Ovulatory Patients during Clomiphene Citrate Induction of Ovulation in Normogonadotropic Oligoamenorrheic Infertility*
}

\author{
BABEK IMANI, MARINUS J. C. EIJKEMANS, EGBERT R. TE VELDE, \\ J. DIK F. HABBEMA, AND BART C. J. M. FAUSER \\ Division of Reproductive Medicine, Department of Obstetrics and Gynecology (B.I., B.C.J.M.F.), and \\ Center for Clinical Decision Sciences, Department of Public Health (M.J.C.E., J.D.F.H.), Erasmus \\ University Medical Center Rotterdam, 3015 GD Rotterdam; and the Department of Obstetrics and \\ Gynecology, University Hospital Utrecht (E.R.t.V.), 3015 GD Utrecht, The Netherlands
}

\begin{abstract}
The present prospective follow-up study was designed to identify whether clinical, endocrine, or ultrasound characteristics assessed by standardized initial screening of normogonadotropic oligo/amenorrheic infertile patients could predict conception in 160 women who reached ovulation after clomiphene citrate (CC) medication. Additional inclusion criteria were total motile sperm count of the partner above 1 million and a negative history for any tubal disease. Daily CC doses of $50 \mathrm{mg}$ (increasing up to $150 \mathrm{mg}$ in case of absent ovarian response) from cycle days 3-7 were used. First conception (defined as a positive urinary pregnancy test) was the end point for this study. A cumulative conception rate of $73 \%$ was reached within 9 CC-induced ovulatory cycles. Patients who did conceive presented more frequently with lower age $(P<0.0001)$ and amenorrhea $(P<0.05)$ upon initial screening. In a univariate analysis, patients with elevated initial serum LH concentrations ( $>7.0 \mathrm{IU} / \mathrm{L})$ had a higher probability of
\end{abstract}

conceiving $(P<0.01)$. In a multivariate analysis, age and cycle history (oligomenorrhea $v s$. amenorrhea) were identified as the only significant parameters for prediction of conception.

These observations suggest that there is more to be gained from CC ovulation induction in younger women presenting with profound oligomenorrhea or amenorrhea. Screening characteristics involved in the prediction of ovulation after CC medication in normogonadotropic oligo/amenorrheic patients (body weight and hyperandrogenemia, as shown previously) are distinctly different from predictors of conception in ovulatory CC patients (age and the severity of cycle abnormality). This disparity suggests that the FSH threshold (magnitude of FSH required for stimulation of ongoing follicle growth and ovulation) and oocyte quality (chances for conception in ovulatory cycles) may be differentially regulated. (J Clin Endocrinol Metab 84: 1617$1622,1999)$
$\mathrm{T}$ HE SYNTHETIC antiestrogen clomiphene citrate (CC) represents an easy to use, convenient, inexpensive, and safe first choice medication in normogonadotropic oligo/ amenorrheic infertility (WHO group 2) (1). Life-table analysis of pregnancy rates after CC medication and prediction of treatment outcome have been the subject of extensive investigation (2-10). Cumulative pregnancy rates after CC treatment between $37-97 \%$ have been reported $(3,4,6)$. A positive correlation was established between body weight and the $\mathrm{CC}$ dose required to induce ovulation $(5,10)$. Moreover, recent studies have indicated that body mass index (BMI) is significantly higher in nonresponders $(7,10)$. Limited information is available, however, concerning the predictive value of initial screening characteristics for treatment outcome (11), and previous investigators were unable to identify predictors for conception after CC induction of ovulation $(6,8,10)$. All the above-mentioned studies focused on

Received October 29, 1998. Revision received January 15, 1999. Accepted February 12, 1999.

Address all correspondence and requests for reprints to: Prof. B. C. J. M. Fauser, M.D., Ph.D., Division of Reproductive Medicine, Department of Obstetrics and Gynecology, Erasmus University Medical Center Rotterdam, Dr. Molewaterplein 40, 3015 GD Rotterdam, The Netherlands. E-mail: fauser@gyna.azr.nl.

* This work was supported by the Stichting Voortplantingsgeneeskunde Rotterdam and an unrestricted research grant from Ferring Nederland BV. the prediction of treatment outcome in the entire group of infertile patients who started with CC medication. In contrast, we focused separately on the prediction of ovulation after CC administration (12) and the prediction of conception in ovulatory CC-treated women. This approach seems more appropriate, because statistical bias due to selective drop out from the study for reasons of persistent anovulation despite increasing doses of CC medication is eliminated.

Our group could recently establish that obese hyperandrogenic amenorrheic patients are more likely to be resistant to CC medication (12). We now report on initial clinical, endocrine, and sonographic screening characteristics of normogonadotropic oligomenorrheic or amenorrheic infertile women achieving ovulatory cycles after CC medication in an attempt to identify factors predicting chances for conception in these patients. The separate focus on the prediction of conception and ovulation after CC treatment may allow differentiation among factors affecting oocyte quality independently from follicle development.

\section{Subjects and Methods \\ Subjects and study protocol}

Between February 1993 and December 1997, 160 couples presenting with oligomenorrhea (bleeding intervals between 35 days and 6 months) or amenorrhea (bleeding interval $>6$ months) and infertility attending our unit were included in the present study. Additional inclusion criteria were 1) serum FSH levels within normal limits $(1-10 \mathrm{IU} / \mathrm{L})(1,13,14)$ 
and normal serum PRL and TSH levels, 2) spontaneous menses or positive bleeding response to progestagen withdrawal, 3) ovulatory cycles after CC induction of ovulation, 4) BMI (weight divided by height squared) greater than 18,5 ) age between $19-40 \mathrm{yr}, 6$ ) a total motile sperm count $[\mathrm{TMC}=$ ejaculate volume (milliliters) $\times$ sperm concentration $\left(10^{6} / \mathrm{mL}\right) \times$ percentage of progressive motile sperm] of the partner above 1 million (15), 7) negative history for any tubal pathology, and 8) no indication for intrauterine insemination. Study approval was obtained from the human subject committee of the Dijkzigt Hospital/ Erasmus University, and informed consent was obtained from all subjects included. A standardized clinical, endocrine, and sonographic screening took place before initiation of induction of ovulation with CC medication.

Ovulation after CC treatment was assessed by midluteal serum progesterone $(\mathrm{P})$ levels above $25 \mathrm{nmol} / \mathrm{L}$, combined with transvaginal sonographic monitoring of follicle growth until visualization of a preovulatory follicle (mean diameter, $>18 \mathrm{~mm}$ ) and subsequent disappearance or biphasic basal body temperature charts, as described previously (12). Clomiphene citrate was administered at a daily dose of $50 \mathrm{mg}$ (increased to 100 and $150 \mathrm{mg}$ in subsequent cycles in the case of absent ovarian response) from cycle days 3-7 after initiation of spontaneous or progestin-induced withdrawal bleeding. Conception was defined as a positive urinary pregnancy test (Clearview, hCG II, Unipath Ltd., Bedford, UK) more than 3 days after the expected menses, and ongoing pregnancy was defined as sonographic assessment of an intrauterine gestational sac with positive heart beat.

History and clinical screening included assessment of duration of infertility, whether infertility was primary or secondary, cycle history, previous medication and/or surgery, and BMI. Endocrine screening included serum assays of FSH, LH, estradiol $\left(\mathrm{E}_{2}\right)$, testosterone $(\mathrm{T})$, androstenedione (AD), sex hormone-binding globulin (SHBG), and P. Fasting venous blood samples were taken on a random day between $0800-1000 \mathrm{~h}$, as indicated previously (12). Blood samples were centrifuged within $2 \mathrm{~h}$ after withdrawal and were stored at $-20 \mathrm{C}$ until assayed. Serum LH and FSH levels were measured by immunofluorometric assay (Amerlite, Ortho-Clinical Diagnostics, Amersham, Aylesbury, UK), as described previously (14). P levels were measured by RIA, as described previously (16). Serum $\mathrm{E}_{2}, \mathrm{~T}$, $\mathrm{AD}$, and SHBG levels were estimated using RIA kits provided by Diagnostic Products (Los Angeles, CA), as described previously (17). Intra- and interassay coefficients of variation were less than $3 \%$ and $8 \%$ for $\mathrm{FSH}$, less than $5 \%$ and $15 \%$ for $\mathrm{LH}$, less than $16 \%$ and $17 \%$ for $\mathrm{P}$, less than $5 \%$ and $7 \%$ for $\mathrm{E}_{2}$, less than $3 \%$ and $5 \%$ for $\mathrm{T}$, less than $8 \%$ and $11 \%$ for $\mathrm{AD}$, and less than $4 \%$ and $5 \%$ for SHBG, respectively. Transvaginal pelvic ultrasound (model EUB-415, Hitachi Medical Corp., Tokyo, Japan) was performed by a single observer (B.I.) and included the assessment of ovarian stroma amount and echogenicity (arbitrarily classified from one to three per ovary), ovarian volume (milliliters), and total number of follicles (both ovaries), as described previously $(13,18)$. Semen analyses were performed according to WHO guidelines (1992) and comprised ejaculate volume (milliliters), number of spermatozoa per $\mathrm{mL}\left(10^{6}\right.$ spermatozoa $\left./ \mathrm{mL}\right)$, percentage of progressive motile spermatozoa, and percentage of normal forms (19).

\section{Data analysis}

A $P$ value of 0.05 was chosen as the threshold level for statistical significance. Cox regression has been used for life-table analysis of conception rates during CC treatment (20). The number of ovulatory CC treatment cycles was the time variable for multivariate analyses. Censoring was defined as definitive discontinuation of CC therapy without conception or end of follow-up (February 1998). To analyze the effect of the severity of cycle abnormality on chances of conceiving after CC treatment, we arbitrarily divided the cycle histories of the patients into four categories; $5-6$ weeks $(\mathrm{n}=56), 6-9$ weeks $(\mathrm{n}=50), 9-26$ weeks $(\mathrm{n}=$ $25)$, and greater than 26 weeks (i.e. amenorrhea) $(n=29)$. The univariate relation was assessed between the variables listed in Table 1 and the time interval between the first ovulation after CC medication and conception using the Kaplan-Meier method (21) for categorical and the Cox regression (20) for continuous variables. The log-rank test has been used to denote statistical significance in life-table analyses. The multivariate analysis was performed with the method of forward stepwise selection to gain a better insight into the interdependence between initial screening parameters. This method can explain why a variable that was significantly different in univariate analysis was not selected in the final model. The prognostic impact of variables was expressed as a fecundability ratio, which is equivalent to the hazard ratio in survival analysis. For instance, a fecundability ratio of 0.9 for an unfavorable group means that the conception rate per ovulatory CC treatment cycle is $10 \%$ lower compared to that in the favorable group. In some couples $(n=25)$, no sperm analysis was performed because of the short time interval between initiation of CC medication and conception. A statistical imputation technique has been applied using multiple conditional mean imputation to fill in these missing sperm parameters (22). The value of semen parameters was estimated using the time until conception and patient characteristics related to sperm parameters in the nonmissing group. Data were analyzed using the commercially available software package SPSS, Inc. (Chicago, IL).

\section{Results}

A total of 82 women (51\% of the ovulatory group) conceived, and $73(46 \%)$ reached an ongoing pregnancy from the total of 160 patients fulfilling the in/exclusion criteria. Sixty-nine were singleton and 4 were twin pregnancies (data not shown). Initial screening parameters of 9 patients who had a miscarriage after CC (11\% of overall CC conceptions) were not different from those of the remaining 73 patients who reached an ongoing pregnancy (data not shown). One woman who conceived (twin pregnancy) during her first CC treatment cycle was frequently monitored on an out-patient basis due to abdominal discomfort
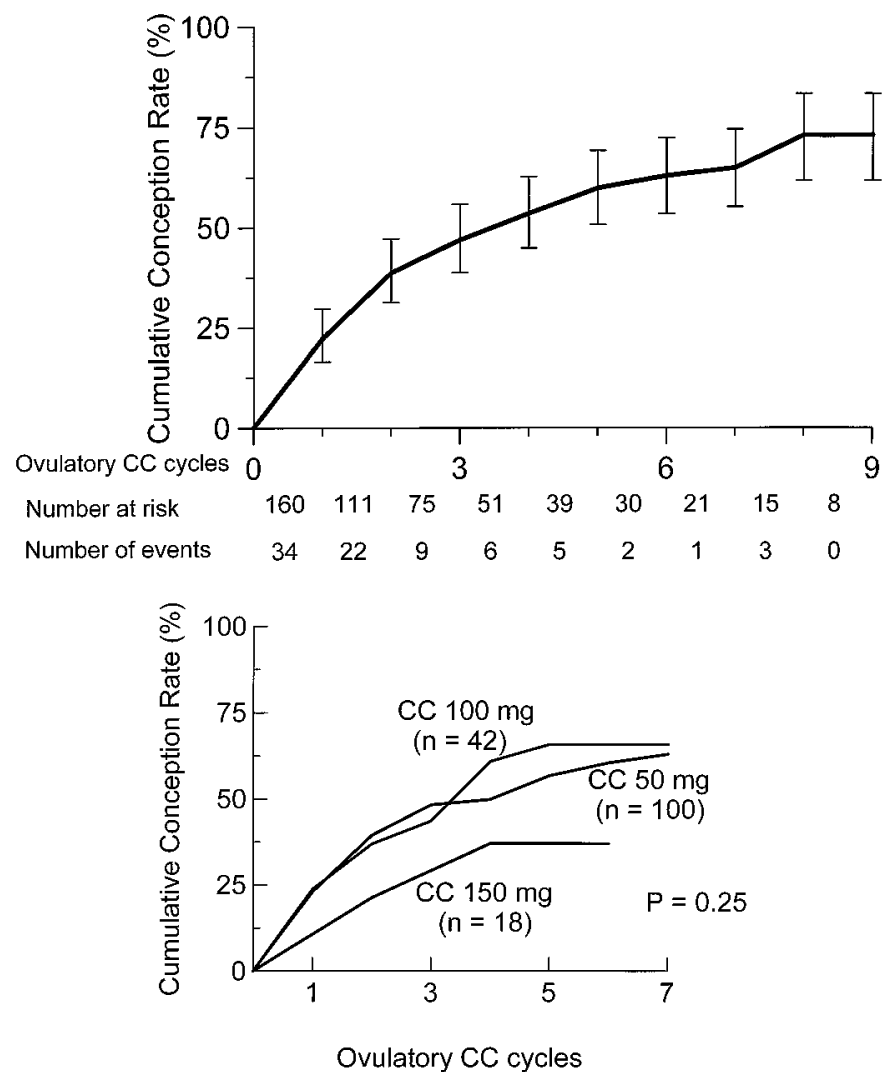

FIG. 1. Life-table analysis of CCR in 160 normogonadotropic oligoamenorrheic infertile patients who ovulated after CC medication. CCR (including absolute number of patients at risk and number of events (conceptions)) are presented for the total study group (upper panel; vertical lines represent $95 \%$ confidence intervals) and separately for women who reached ovulatory CC cycles with 50,100 , or $150 \mathrm{mg}$ daily for 5 subsequent days (lower panel). $\mathrm{N}$ represents the initial number of patients at risk per dose group. $P=\log$-rank test $P$ value. 
and enlarged ovaries. There was no case of severe ovarian hyperstimulation syndrome.

The life-table analysis of cumulative conception rates (CCR) of patients who ovulated after CC are indicated in Fig. 1 for the total group, and separately for different dose groups. A cumulative conception rate of $47 \%$ was reached within three cycles from first ovulation, and a CCR of $73 \%$ was reached within nine CC-induced ovulatory cycles. Patients using daily doses of 50, 100 , and $150 \mathrm{mg}$ CC reached cumulative conception rates of $57 \%, 66 \%$, and $38 \%$ within 5 ovulatory cycles, respectively $\left(P_{\log \text { rank }}=0.25 ;\right.$ Fig. 1$)$. At higher doses, chances for conception and ongoing pregnancy are not statistically significantly reduced, although absolute CCR $(\mathrm{n}=18)$ were low in the 150-mg CC group. The overall mean duration of follow-up was $4 \pm 3$ months and $3.2 \pm 2.6$ ovulatory CC cycles. Initial screening characteristics of the overall group of patients who ovulated after CC and separately for those women who conceived $(\mathrm{n}=82)$ vs. those who did not $(\mathrm{n}=78)$ are depicted in Table 1. Age, the severity of cycle abnormality (oligomenorrhea $v s$. amenorrhea), and cycle duration, arbitrarily classified in four categories (see also Materials and Methods), were significantly different in univariate analysis. Age (cut-off of $30 \mathrm{yr}$ ), cycle history (oligomenorrhea vs. amenorrhea), and initial serum LH level (cut-off level of 7.0 IU/L) in univariate analyses for CCR are depicted in Fig. 2. The percentages of ongoing pregnancies per conception for patients with elevated (initial serum LH level $\geq 7.0 \mathrm{IU} / \mathrm{L}$ ) or normal initial serum LH levels were $84.8 \%$ and $94.4 \%$, respectively ( $P$ value for difference in proportion ongoing pregnancies $=0.16$, and $95 \%$ confidence interval for difference $=-3 \%$ to $23 \%$ ). The cut-off value for normal (i.e. 7.0 $\mathrm{IU} / \mathrm{L}$ ) was chosen on the basis of a previous study from our group in normoovulatory controls (mean \pm 1 sD) (23).

A total number of 159 patients had complete data on the variables used in the multivariate analyses. Univariate analysis and forward stepwise multivariate analyses of all initial parameters for the prediction of chances to conceive in ovulatory patients treated with CC are depicted in Table 2. During the stepwise multivariate analysis for the prediction of chances to conceive, age, and cycle history (amenorrhea vs. oligomenorrhea) entered into the model (steps 1 and 2, respectively). The multivariate-adjusted fecundability ratio for age was 0.90 (95\% confidence interval, 0.85-0.95), and that for amenorrhea was $0.54 \quad(95 \%$ confidence interval, 0.32-0.93).

\section{Discussion}

The present prospective follow up study was designed to evaluate whether initial screening characteristics of 160 normogonadotropic oligo/amenorrheic infertile women could predict conception during ovulatory CC-induced cycles. Although CC medication has been the focus of prevalent research, limited information is available regarding the prediction of conception as treatment outcome (11). Reported cumulative pregnancy rates vary between 37-97\%. Most studies, however, suffer from methodological difficulties and different inclusion/exclusion criteria. For the first time, our group has focused on ovulation and conception in sep-

TABLE 1. Initial clinical, endocrine, and ultrasound screening characteristics and sperm parameters of partners (median and range) of 160 normogonadotropic oligomenorrheic or amenorrheic infertile women who ovulated after CC induction of ovulation (overall group) and did or did not (CC failure) conceive

\begin{tabular}{|c|c|c|c|c|}
\hline Screening parameters & $\begin{array}{l}\text { Overall group } \\
(\mathrm{n}=160)\end{array}$ & $\begin{array}{c}\text { Conceived } \\
(\mathrm{n}=82 ; 51 \%)\end{array}$ & $\begin{array}{c}\text { CC failure } \\
(\mathrm{n}=78 ; 49 \%)\end{array}$ & $P$ value $^{a}$ \\
\hline \multicolumn{5}{|l|}{ Clinical } \\
\hline Age (yr) & $28 \pm 4$ & $27 \pm 4$ & $29 \pm 4$ & 0.0001 \\
\hline Infertility duration (yr) & $1.9 \pm 2.3$ & $1.6 \pm 1.4$ & $2.2 \pm 2.9$ & 0.23 \\
\hline Primary infertility (n) & 116 & 62 & 54 & 0.40 \\
\hline Amenorrhea $(\mathrm{n})$ & 29 & $18(62)$ & $11(38)$ & 0.04 \\
\hline Bleeding interval in 4 categories & & & & $\overline{0.05}$ \\
\hline 5-6 weeks, n $(\%)$ & $56(35)$ & 22 & 34 & \\
\hline $6-9$ weeks, n (\%) & $50(31)$ & 29 & 21 & \\
\hline $9-26$ weeks, n $(\%)$ & $25(16)$ & 13 & 12 & \\
\hline$>26$ weeks, n $(\%)$ & $29(18)$ & 18 & 11 & \\
\hline BMI $\left(\mathrm{kg} / \mathrm{m}^{2}\right)$ & $26 \pm 6$ & $26 \pm 6$ & $25 \pm 6$ & 0.46 \\
\hline \multicolumn{5}{|l|}{ Endocrine } \\
\hline LH (IU/L) & $7.6 \pm 4.2$ & $8.2 \pm 4.3$ & $6.9 \pm 4.0$ & 0.11 \\
\hline $\mathrm{T}(\mathrm{nmol} / \mathrm{L})$ & $2.3 \pm 1.0$ & $2.3 \pm 1.0$ & $2.3 \pm 1.0$ & 0.85 \\
\hline $\mathrm{AD}(\mathrm{nmol} / \mathrm{L})$ & $15.0 \pm 6.9$ & $15.8 \pm 7.9$ & $14.0 \pm 5.7$ & 0.16 \\
\hline $\mathrm{FAI}^{c}$ & $5.4 \pm 3.9$ & $5.5 \pm 4.1$ & $5.1 \pm 3.7$ & 0.20 \\
\hline SHBG (nmol/L) & $56 \pm 31$ & $54 \pm 27$ & $58 \pm 35$ & 0.24 \\
\hline $\mathrm{E}_{2}(\mathrm{pmol} / \mathrm{L})$ & $259 \pm 175$ & $229 \pm 145$ & $290 \pm 198$ & 0.10 \\
\hline \multicolumn{5}{|l|}{ Ultrasound } \\
\hline Mean ovarian vol (mL) & $9.3 \pm 3.7$ & $9.2 \pm 3.7$ & $9.4 \pm 3.7$ & 0.97 \\
\hline Mean follicle no. & $12 \pm 5$ & $12 \pm 5$ & $12 \pm 5$ & 0.48 \\
\hline Total stroma score ${ }^{d}$ & $3.2 \pm 1.1$ & $3.1 \pm 1.1$ & $3.3 \pm 1.2$ & 0.66 \\
\hline Total motile sperm count (TMC) & $73(1.1-492)$ & $75(1.5-303)$ & $72(1.1-492)$ & $0.32^{e}$ \\
\hline$\%$ Normal morphology & $24(1-50)$ & $20(1-50)$ & $25(1-50)$ & $0.34^{e}$ \\
\hline \multicolumn{5}{|c|}{$\begin{array}{l}\text { Values are the mean } \pm \mathrm{SD} \text {. Underlined values are statistically significant. } \\
{ }^{a} \text { Comparison of CC-conceived } v \text { s. CC failure (univariate Cox regression). } \\
{ }^{b} \text { Chances to conceive differ among four categories of bleeding interval. } \\
c^{c} \mathrm{FAI}=\mathrm{T} \times 100 / \mathrm{SHBG} \text {. } \\
{ }^{d} \text { Arbitrarily defined as one to three per ovary (both ovaries added). } \\
{ }^{e} \text { Computed with multiple imputation of missing values. }\end{array}$} \\
\hline
\end{tabular}



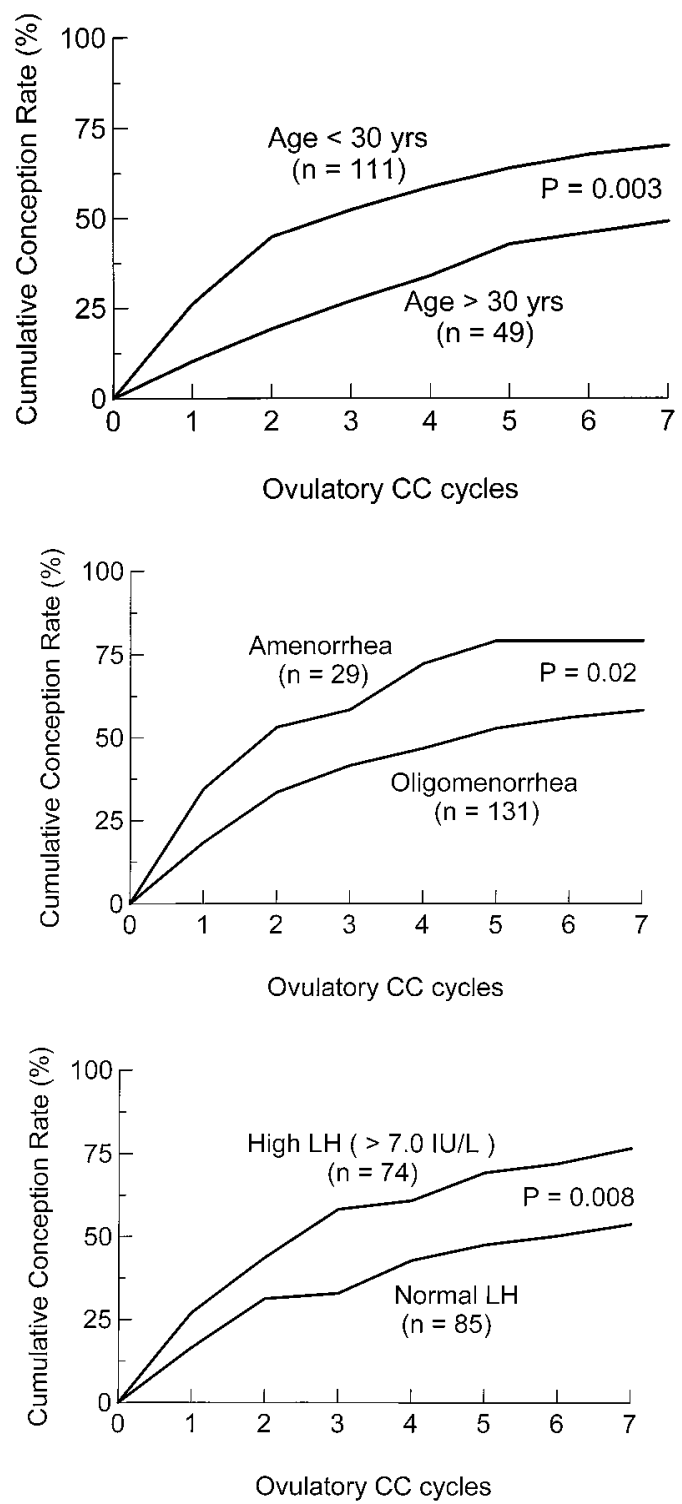

FIG. 2. Univariate analysis of CCR in 160 normogonadotropic oligoamenorrheic infertile patients per ovulatory CC cycle. Initial screening parameters shown are 1) patient's age (cut-off level at 30 yr; upper panel), 2) cycle history (oligomenorrhea vs. amenorrhea; middle panel), and 3) initial serum LH concentrations (cut-off level of 7.0 IU/L; lower panel). $\mathrm{n}$ represents the initial number of patients at risk. $P=\log$-rank test $P$ value.

arate steps, taking into account that a significant proportion $(23 \%)$ of patients who remain anovulatory after CC medication (12) have no chance of conception. Inclusion of these patients in a study focusing on conception causes statistical bias. This separate focus may offer a better insight into the potential predictive power of initial screening characteristics in a heterogeneous group of normogonadotropic oligo/amenorrheic infertile women (WHO class 2) for CC-induced follicle growth and ovulation, separately from conception.

In the present study, CCR of $63 \%$ within six cycles and $73 \%$ within nine ovulatory CC-induced cycles have been reached. Two thirds of patients who conceived reached this end point within the first three ovulatory CC treatment cycles. This is
TABLE 2. Forward stepwise multivariate analyses of initial screening characteristics for the prediction of chances to conceive in 159 normogonadotropic oligo-amenorrheic infertile women who ovulated after CC induction of ovulation

\begin{tabular}{|c|c|c|c|}
\hline \multirow{2}{*}{ Analyses steps } & \multirow{2}{*}{$\begin{array}{l}\text { Univariate: } \\
\qquad 0^{a}\end{array}$} & \multicolumn{2}{|c|}{ Multivariate } \\
\hline & & 1 & 2 \\
\hline \multicolumn{4}{|l|}{ Screening parameters } \\
\hline \multicolumn{4}{|l|}{ Clinical } \\
\hline Age (yr) & 0.0001 & In model & In model \\
\hline Amenorrhea $(\mathrm{n}=29)$ & 0.04 & 0.02 & In model \\
\hline $\begin{array}{l}\text { Bleeding interval (in four } \\
\text { categories) }\end{array}$ & 0.05 & $\overline{0.06}$ & 0.30 \\
\hline \multicolumn{4}{|l|}{ Endocrine } \\
\hline LH (IU/L) & 0.11 & 0.36 & 0.26 \\
\hline $\mathrm{FAI}^{b}$ & 0.20 & 0.56 & 0.38 \\
\hline $\mathrm{AD}(\mathrm{nmol} / \mathrm{L})$ & 0.16 & 0.38 & 0.15 \\
\hline $\mathrm{E}_{2}(\mathrm{pmol} / \mathrm{L})$ & 0.10 & 0.26 & 0.39 \\
\hline
\end{tabular}

Numbers are $P$ values for inclusion in the model. Underlined numbers are significant at $P<0.05$.

${ }^{a}$ Only screening parameters with a univariate $P \leq 0.2$ (see Table 1) are shown. In the univariate analysis (step 0 ), three variables reach statistical significance (underlined). In step 1 of the multivariate analysis the variable with the highest prognostic information (age) is selected. After the first step, amenorrhea still reaches statistical significance and, therefore, is selected in the second step. Thereafter, no additional variable is statistically significant anymore, indicating that the model cannot be improved by selecting a subsequent parameter.

${ }^{b} \mathrm{FAI}=\mathrm{T} \times 100 /$ SHBG.

in agreement with previous reports in the literature regarding CC $(3,24,25)$ and is similar to spontaneous conception chances in normoovulatory women (26). This is also comparable to conception rates reported for exogenous gonadotropin induction of ovulation (27-29) in anovulatory infertile patients. These observations strongly suggest that the overall detrimental effects of CC on cervical mucus production or endometrial receptivity and subsequent implantation are limited with daily CC doses up to $150 \mathrm{mg}$. Although the CCR seems to be lower in the high dose CC group, this finding was not statistically significant. It should be noted that the sample size of this group was limited, so actual differences cannot be excluded.

Previous studies were unable to identify predictors for conception in CC induction of ovulation in normogonadotropic infertile women $(6,8,10)$. In the present study, age and cycle history (amenorrhea or oligomenorrhea) were significantly different comparing patients who conceived vs. those who did not during CC-induced ovulatory cycles. Multivariate analyses revealed a final model including age and cycle history. The predictive power of age was highest. The area under the receiver operating characteristics curve of the final model including these two factors reached 0.68 (data not shown), which is substantially lower than that in the previous model predicting ovulation after CC (0.82) (12). For reasons of clarity, the forward stepwise approach was chosen. Backward stepwise analysis was also applied, resulting in the same final model (data not shown). Young patients have a higher probability to conceive during CC-induced ovulatory cycles. The fecundability rate of the patient decreases by approximately $10 \% / y r$. This is in agreement with reports that indicate that age is an important factor for the prediction of chances for spontaneous conception in untreated nor- 
moovulatory subfertile patients (30-32). Similar findings have been reported for the prediction of chances to conceive after exogenous gonadotropin induction of ovulation (27) and in vitro fertilization treatment (33).

Amenorrheic patients exhibit a 2-fold higher probability to conceive after ovulatory CC cycles compared to oligomenorrheic patients. Patients with longer bleeding intervals also exhibit higher conception chances. We have been unable to find similar reports in the literature regarding induction of ovulation. The most likely explanation seems to be the following. Patients with amenorrhea have an extremely low probability to conceive without intervention due to anovulation before seeking help by a physician. Presumably, the major subfertility factor in these patients is chronic anovulation, which can be resolved temporarily by the use of CC medication. These patients are more likely to be at low risk for any other subfertility factor, such as tubal or sperm dysfunction. Some oligomenorrheic patients may have spontaneous ovulations (34), and some of these women may never seek medical intervention because of spontaneous pregnancies. Their benefit from ovulation induction is an increased chance for conception due to an increased number of ovulations with a fixed interval in a given period of time. Similar observations were made for pregnancy chances after artificial insemination with donor sperm in relation to the sperm quality of the partner. Donor insemination outcome is significantly better in cases with very poor sperm quality (35). One should consider that amenorrheic patients also have a higher probability to remain anovulatory after $\mathrm{CC}$, as demonstrated previously (12). In contrast, regular ovulatory cycles are easier to induce with CC in oligomenorrheic patients, but there is less chance of pregnancy.

In the present study, patients with elevated initial serum LH levels have a significantly higher probability to conceive once ovulatory cycles have been achieved by CC. A recent study also indicated higher initial LH levels in patients who conceived after CC medication (10). In contrast, a poor treatment outcome has been observed in patients with high $\mathrm{LH}$ levels during the follicular phase of CC-induced cycles (8). It should be realized that we report on initial LH levels before initiation of CC medication, rather than during CC-induced cycles. Indeed, elevated LH levels may normalize only during CC-induced ovulatory cycles (36). These observations are in sharp contrast with reports regarding patients with elevated LH who perform poorly during gonadotropin induction of ovulation (28) or in vitro fertilization (37). We previously showed that initial LH concentrations did not predict patients who would remain anovulatory after CC medication (12). The present observation seems to dispute previous beliefs concerning the detrimental effects of elevated LH levels on oocyte maturation and capacity for fertilization. In addition, we did not observe a higher spontaneous abortion rate in patients with high LH levels who conceived after CC medication. This finding is also in contrast with previous reports on the effects of high $\mathrm{LH}$ concentrations on chances for spontaneous abortion after exogenous gonadotropins (38, 39). The predictive power of the initial LH level is poor in case age enters in the final model, which may be due to a correlation of initial LH with age (data not shown). The mechanism of action of CC is not fully elucidated, and the role of $\mathrm{LH}$ in the pathogenesis of ovarian abnormalities remains open for speculation. As an example, female siblings of male patients described with an activating mutation of the $\mathrm{LH}$ receptor (so-called familial male testotoxicosis) seem to be without a clear phenotype (40).

Total motile sperm count is not a predictor in univariate or multivariate analyses of prediction of conception in the present study population. This is in agreement with the observation that a large overlap exists between semen characteristics of males from fertile vs. subfertile couples (15). Moreover, it can be speculated that couples with better sperm parameters have already conceived spontaneously before seeking medical intervention.

In summary, it can be concluded that body weight and hyperandrogenemia are the predominant predictors for ovulation after CC treatment, whereas age and cycle history dictate pregnancy chances in ovulatory women. This stresses for the first time the important concept that follicle growth and oocyte quality (and subsequent capacity to be fertilized in vivo) are differentially regulated during induction of ovulation, confirming observations during in vitro fertilization.

\section{References}

1. WHO. 1993 WHO manual for the standardized investigation and diagnosis of the infertile couple. Cambridge: Cambridge University Press.

2. MacGregor AH, Johnson JE, Bunde CA. 1968 Further clinical experience with clomiphene citrate. Fertil Steril. 19:616-622.

3. Gorlitsky GA, Kase NG, Speroff L. 1978 Ovulation and pregnancy rates with clomiphene citrate. Obstet Gynecol. 51:265-269.

4. Shepard MK, Balmaceda JP, Leija CG. 1979 Relationship of weight to successful induction of ovulation with clomiphene citrate. Fertil Steril. 32:641-645.

5. Lobo RA, Gysler M, March CM, Goebelsmann U, Mishell Jr DR. 1982 Clinical and laboratory predictors of clomiphene response. Fertil Steril. 37:168-174.

6. Hammond MG, Halme JK, Talbert LM. 1983 Factors affecting the pregnancy rate in clomiphene citrate induction of ovulation. Obstet Gynecol. 62:196-202.

7. Polson DW, Kiddy DS, Mason HD, Franks S. 1989 Induction of ovulation with clomiphene citrate in women with polycystic ovary syndrome: the difference between responders and nonresponders. Fertil Steril. 51:30-34.

8. Shoham Z, Borenstein R, Lunenfeld B, Pariente C. 1990 Hormonal profiles following clomiphene citrate therapy in conception and nonconception cycles. Clin Endocrinol (Oxf). 33:271-278

9. Opsahl MS, Robins ED, O'Connor DM, Scott RT, Fritz MA. 1996 Characteristics of gonadotropin response, follicular development, and endometrial growth and maturation across consecutive cycles of clomiphene citrate treatment. Fertil Steril. 66:533-539.

10. Kousta E, White DM, Franks S. 1997 Modern use of clomiphene citrate in induction of ovulation. Hum Reprod Update. 3:359-365.

11. Adashi EY. 1996 Ovulation induction: clomiphene citrate. In: Adashi EY, Rock JA, Rosenwaks Z, eds. Reproductive endocrinology: survey and technology. Philadelphia: Lippincott-Raven; 1182-1206.

12. Imani B, Eijkemans MJ, te Velde ER, Habbema JD, Fauser BC. 1998 Predictors of patients remaining anovulatory during clomiphene citrate induction of ovulation in normogonadotropic oligoamenorrheic infertility. J Clin Endocrinol Metab. 83:2361-2365.

13. van Santbrink EJ, Hop WC, van Dessel TJ, de Jong FH, Fauser BC. 1995 Decremental follicle-stimulating hormone and dominant follicle development during the normal menstrual cycle. Fertil Steril. 64:37-43.

14. Schipper I, de Jong FH, Fauser BC. 1998 Lack of correlation between maximum early follicular phase serum follicle stimulating hormone concentrations and menstrual cycle characteristics in women under the age of 35 years. Hum Reprod. 13:1442-1448.

15. Ombelet W, Bosmans E, Janssen M, et al. 1997 Semen parameters in a fertile vs. subfertile population: a need for change in the interpretation of semen testing. Hum Reprod. 12:987-993.

16. de Jong FH, Baird DT, van der Molen HJ. 1974 Ovarian secretion rates of oestrogens, androgens and progesterone in normal women and in women with persistent ovarian follicles. Acta Endocrinol (Copenh). 77:575-587.

17. Fauser BC, Pache TD, Lamberts SW, Hop WC, de Jong FH, Dahl KD. 1991 Serum bioactive and immunoreactive luteinizing hormone and follicle-stimulating hormone levels in women with cycle abnormalities, with or without polycystic ovarian disease. J Clin Endocrinol Metab. 73:811-817.

18. Pache TD, Wladimiroff JW, Hop WC, Fauser BC. 1992 How to discriminate 
between normal and polycystic ovaries: transvaginal US study. Radiology. 183:421-423.

19. World Health Organization. 1992 WHO laboratory manual for the examination of human semen and sperm-cervical mucus interaction, 3rd ed. Cambridge: Cambridge University Press.

20. Cox DR. 1972 Regression models and life tables. J R Statist Soc. B34:187-220.

21. Kaplan EL, Meier P. 1958 Nonparametric estimation from incomplete observations. J Am Statist Assoc. 53:457-481.

22. Rubin DB. Multiple imputation in sample surveys: a phenomenological Baysian approach to nonresponse. Proc Surv Res Methods Sect Am Stat Assoc. 1978; 20-34.

23. van Santbrink EJ, Hop WC, Fauser BC. 1997 Classification of normogonadotropic infertility: polycystic ovaries diagnosed by ultrasound vs. endocrine characteristics of polycystic ovary syndrome. Fertil Steril. 67:452-458.

24. Garcia J, Jones GS, Wentz AC. 1977 The use of clomiphene citrate. Fertil Steril. 28:707-717.

25. Gysler M, March CM, Mishell DR, Jr, Bailey EJ. 1982 A decade's experience with an individualized clomiphene treatment regimen including its effect on the postcoital test. Fertil Steril. 37:161-167.

26. Tietze C. 1968 Fertility after discontinuation of intrauterine and oral contraception. Int J Fertil. 13:385-389.

27. Dor J, Itzkowic DJ, Mashiach S, Lunenfeld B, Serr DM. 1980 Cumulative conception rates following gonadotropin therapy. Am J Obstet Gynecol. 136:102-105

28. Hamilton-Fairley D, Kiddy D, Watson H, Sagle M, Franks S. 1991 Low-dose gonadotrophin therapy for induction of ovulation in 100 women with polycystic ovary syndrome. Hum Reprod. 6:1095-1099.

29. van Santbrink EJ, Donderwinkel PF, van Dessel TJ, Fauser BC. 1995 Gonadotrophin induction of ovulation using a step-down dose regimen: singlecentre clinical experience in 82 patients. Hum Reprod. 10:1048-1053.
30. Eimers JM, te Velde ER, Gerritse R, et al. 1994 The prediction of the chance to conceive in subfertile couples. Fertil Steril. 61:44-52.

31. Collins JA, Burrows EA, Wilan AR. 1995 The prognosis for live birth among untreated infertile couples. Fertil Steril. 64:22-28.

32. Scott RT, Opsahl MS, Leonardi MR, Neall GS, Illions EH, Navot D. 1995 Life table analysis of pregnancy rates in a general infertility population relative to ovarian reserve and patient age. Hum Reprod. 10:1706-1710.

33. Templeton A, Morris JK, Parslow W. 1996 Factors that affect outcome of in-vitro fertilisation treatment. Lancet. 348:1402-1406.

34. Minakami H, Abe N, Izumi A, Tamada T. 1988 Serum luteinizing hormone profile during the menstrual cycle in polycystic ovarian syndrome. Fertil Steril. 50:990-992.

35. Emperaire JC, Gauzere-Soumireu E, Audebert AJ. 1982 Female fertility and donor insemination. Fertil Steril. 37:90-93.

36. Eden JA, Place J, Carter GD, Alaghband-Zadeh J, Pawson ME. 1989 The role of chronic anovulation in the polycystic ovary syndrome: normalization of sex-hormone-binding globulin levels after clomiphene- induced ovulation. Clin Endocrinol (Oxf). 30:323-332.

37. Howles CM, Macnamee MC, Edwards RG, Goswamy R, Steptoe PC. 1986 Effect of high tonic levels of luteinising hormone on outcome of in-vitro fertilisation. Lancet. 2:521-522.

38. Homburg R, Armar NA, Eshel A, Adams J, Jacobs HS. 1988 Influence of serum luteinising hormone concentrations on ovulation, conception, and early pregnancy loss in polycystic ovary syndrome. Br Med J. 297:1024-1026.

39. Regan L, Owen EJ, Jacobs HS. 1990 Hypersecretion of luteinising hormone, infertility, and miscarriage. Lancet. 336:1141-1144.

40. Fauser BC, Conway GS, Franks S. 1999 Genetics of female reproductive dysfunction. In: Fauser BC, Rutherford AJ, Strauss III JF, Steirteghem AC, eds Molecular biology in reproductive medicine. London: Parthenon; 451-478. 